\title{
FEMININO EM QUESTÃO: DIÁLOGOS CONTEMPORÂNEOS ENTRE PSICANÁLISE E FEMINISMO
}

Feminism in Question: Contemporary Dialogues between Psychoanalysis and Feminism

Femenino en Cuestión: Diálogos Contemporáneos entre Psicoanálisis y Feminismo

Femme en Question : Dialogues Contemporains entre Psychanalyse et Féminisme

doi $10.5020 / 23590777 . r s . v 20 i E s p 2 . e 8974$

\section{Paula Affonso de Oliveira (}

Psicóloga do Instituto Federal de Educação, Ciência e Tecnologia do Pará. Mestre em Psicologia e doutoranda pelo Programa de Pós-Graduação em Psicologia da Universidade Federal do Pará na linha de pesquisa "Psicanálise, teoria e clínica".

\section{Roseane Freitas Nicolau}

Psicanalista, Psicóloga, Doutora em Sociologia (UFC) e Pós-Doutora em Teoria Psicanalítica (UFRJ). Prof da Faculdade e do Programa de Pós-Graduação em Psicologia da UFA, membro da Escola Letra Freudiana e coordenadora do GT da ANPEPP Psicanálise, Política e Clínica.

\begin{abstract}
$\mathrm{O}$ artigo tem por objetivo apresentar as discussões teóricas entre a psicanálise e o movimento feminista, em especial no que tange aos conceitos freudianos e lacanianos sobre a posição feminina e seus ordenadores simbólicos, como a primazia do falo - frequentemente associado pela crítica feminista ao pênis, a um falocentrismo teórico e seus desdobramentos. No centro desse debate, o feminino impõese com um questionamento à psicanálise: rompendo os limites de uma lógica fálica, seria este um caminho para pensar a alteridade? Em tempos de levantes conservadores, resgatar essa discussão é propor um espaço de abertura para pensar a diferença.
\end{abstract}

Palavras-chave: feminino; movimento feminista; psicanálise.

Abstract

The article aims to present the theoretical discussions between psychoanalysis and the feminist movement, especially concerning Freudian and Lacanian concepts about the female position and its symbolic originators, such as the primacy of the phallus - often associated by the feminist criticism to the penis, theoretical phallocentrism, and its consequences. At the center of this debate, the feminine imposes itself with a questioning of psychoanalysis: breaking the limits of a phallic logic, would this be a way to think about otherness? In times of conservative uprisings, to rescue this discussion is to propose an opening space to think about the difference.

Keywords: female; feminist movement; psychoanalysis.

\section{Resumen}

El trabajo tiene el objetivo de presentar las discusiones teóricas entre el psicoanálisis y el movimiento feminista, en especial a lo que se refiere a los conceptos freudianos y lacanianos sobre la posición femenina y sus ordenadores simbólicos, como la primacía del falo frecuentemente asociado por la crítica femenina al pene, al falocentrismo teórico y sus desdoblamientos. En el centro de este debate, el femenino se impone con un cuestionamiento al psicoanálisis: rompiendo los límites de una lógica fálica, ¿sería este un camino para pensar la alteridad? En tiempos de levantes conservadores, rescatar esta discusión es proponer un espacio de apertura para la diferencia. Em tempos de levantes conservadores, resgatar essa discussão é propor um espaço de abertura para pensar a diferença. 
Palabras clave: femenino; movimiento feminista; psicoanálisis.

\section{Résumé}

L'article vise à présenter les discussions théoriques entre la psychanalyse et le mouvement féministe, notamment en ce qui concerne les concepts freudiens et lacaniens sur la position féminine et ses symboles, comme la primauté du phallus - souvent associée par la critique féministe au pénis, c'est-à-dire à un phallocentrisme théorique et ses conséquences. Au centre de ce débat, le féminin s'impose avec une question à la psychanalyse : briser les limites d'une logique phallique, s'agit d'une manière de penser l'altérité ? Dans une période de soulèvements conservateurs, soulever cette discussion est proposer un espace d'ouverture pour réfléchir à la différence.

Mots-clés : femme ; mouvement féministe ; psychanalyse.

A regulação do corpo e da sexualidade pelo Estado, especialmente da mulher, não é um artifício inédito, ou mesmo recente, no entanto assumiu novos contornos com a escalada conservadora que ganha espaço no Brasil e no mundo. Manifestações reacionárias ao debate público acerca do reconhecimento das minorias são cada vez mais frequentes, especialmente no que tange à luta por direitos sexuais e respeito à diferença.

Paradoxalmente, ao mesmo tempo em que se intensificam as manifestações a favor da liberdade sexual, da diversidade e dos direitos humanos - como as reivindicações pró-aborto ocorridas na Argentina, a Marcha das Mulheres em diferentes países americanos e europeus, e o Ní una menos em cidades da Argentina, Chile e Uruguai -, os discursos contrários a essas populações se recrudescem, em uma manobra de manutenção do status quo e de privilégios pela elite política majoritariamente masculina, rica e branca, mesmo quel irrompeu em crises histéricas no século XIX às custas da promoção de pequenas reformas de caráter liberal que amansem a potência política desses movimentos.

A crítica à dita "ideologia de gênero" como um artifício para doutrinar crianças e jovens no exercício de sua sexualidade fora do padrão binário masculino-feminino, atribuída pelos grupos políticos de direita aos grupos de esquerda, demonstra claramente os contornos dessa discussão, que rechaça qualquer sujeito fora da norma padrão e promove abertamente o apagamento da diversidade sexual em função de um moralismo hipócrita de cunho aparentemente inclusivo. Conforme expressam, não se trata de desrespeito à sexualidade alheia, mas de proteção contra o doutrinamento infantil; assim, a sexualidade permanece aparentemente individual e livre - mantendo os pilares do neoliberalismo -, desde que se mantenha escondida, reprimida e silenciada.

Esse movimento pendular, de abertura e fechamento, com a afirmação da diferença concomitante a escaladas conservadoras e perda de reconhecimento e direitos dos grupos minoritários, traduz-se, no campo da sexualidade, pela tentativa de apagar o sexual, a fantasia e o desejo pela via da promoção de semblantes rígidos do masculino e feminino, reacendendo a importância dos movimentos que se propõem a fazer furo nesse discurso conservador.

O movimento feminista é um desses que possui o potencial de enfrentar esses discursos de ódio ao diferente, produzindo impactos subjetivos e sociais, mesmo que as reivindicações políticas não tenham sido propriamente conquistadas. Político desde seu princípio, o feminismo organiza-se, seja por meio de reivindicações e lutas por garantias de direitos jurídicos, seja com produções e discussões teóricas que fundamentam essas lutas, com temas tais como a posição histórica da mulher na sociedade, as causas da subordinação feminina (Arán, 2009; Saffioti, 2004).

Destacam-se, nessas correntes, as teorias acerca do patriarcado, utilizadas para explicar os processos sociais e históricos que legitimariam a subordinação feminina e a dominação masculina, por meio da ideia da fragilidade e da proteção da mulher por um "homem forte" e do uso efetivo da violência. Aliadas a uma tradição marxista, estas creditam ao sistema capitalista, impregnado pelo discurso patriarcal, a reafirmação do caráter opressor, que coloca a mulher em posição inferior ao homem, ao sustentar a ideologia perene na divisão sexual do trabalho, na qual a mulher ora é segregada ao âmbito doméstico, ora é submetida a uma dupla jornada de emprego e lar, com a desigualdade econômica contribuindo para a manutenção da assimetria de gênero (Saffioti, 2004).

É nessa seara que se destacam, especialmente, os estudos que dizem respeito à sexualidade, questionando outros campos de saber, como a biologia, a medicina e a própria psicanálise (Bento, 2006; Butler, 2013). O diálogo com a psicanálise, em especial, desponta como uma terceira via dos estudos de gênero, cuja análise permitiria explicar a produção e reprodução da identidade de gênero no âmbito do sujeito, especialmente a partir do conceito de diferença sexual.

Conforme descreve Cossi (2016), por vezes, a psicanálise é acusada de manter uma visão binária e heteronormativa de sujeito, justamente devido à adoção do conceito de diferença sexual, que se aproximaria mais de uma concepção biológica de humano do que das teses desconstrucionistas pregadas pelo movimento feminista. A noção de simbólico instaurada por 
Lacan (1998a; 2005) é peça-chave nessa discussão pelo seu caráter supostamente patriarcal, que sustentaria uma dominância fálica, frequentemente atrelada ao pênis e ao masculino. Em resposta, a psicanálise reafirma o caráter simbólico do falo e a potência subversiva do sexual que excede os limites de uma lógica fálica com o gozo não-todo.

Contudo, se não há dúvida de que a psicanálise foi criada dando voz e fala ao inconsciente e ao que dele resiste a toda tentativa de normalização, autores pós-freudianos nem sempre se guiaram por esse esteio, por vezes transmutando-a em uma clínica adaptativa. Entre os exemplos, temos as discussões francesas contrárias à adoção homoparental, encampadas por psicanalistas como Pierre Legendre que, em nome da manutenção de uma ordem simbólica, sustentavam a homossexualidade como perversão e negação da diferença sexual, tornando-os inaptos para a adoção (Roudinesco, 2003). Em defesa dos direitos LBGTQI+, afirmou-se a noção de função paterna e materna, que pode ser encarnada por qualquer cuidador, em rechaço a um determinismo anatômico (Perelson, 2006).

Logo, a clínica psicanalítica em especial, mas também o diálogo com outras áreas, são fundamentais para impulsionar avanços teóricos que permitam novas construções para velhos sintomas. De certa forma, a história do debate entre psicanálise e os feminismos é uma história de questionamento e tensão entre campos, que possibilitou - e ainda o faz, de novas maneiras, conforme o debate avança - uma leitura social e subjetiva dos fenômenos de sujeição.

Seguir o caminho dos discursos contemporâneos sobre subjetividades, a partir das discussões entre psicanálise e movimento feminista, em especial no que tange ao feminino, é essencial em tempos de levantes conservadores. A análise do feminino pode problematizar uma concepção de simbólico masculino e repensar a mulher não enquanto essência ou negativo do homem, mas como a posição limítrofe entre o Outro e o para além, como aquilo que faz questão ao social.

O feminino, nesse sentido, constitui um dos temas centrais a esse debate, pois inaugura, como afirma Arán (2009), um novo horizonte para pensar a diferença. Este artigo, portanto, pretende apresentar as discussões entre psicanálise e feminismo, apontando pontos de divergência e aproximação para, enfim, discutir o feminino como ponto de inflexão que permite à psicanálise pensar novos caminhos, menos normativos.

\section{Psicanálise e Feminismo, Travessias Históricas}

Oriundo da teoria política e com o objetivo de analisar a sociedade a partir das desigualdades de gênero, o movimento feminista nasceu da luta política das mulheres pela igualdade de direitos. Nesse sentido, a própria Revolução Francesa pode ser encarada como o gérmen do movimento feminista, ao inaugurar a participação das mulheres na luta por direitos iguais (Roudinesco, 1997). Essa luta das mulheres na revolução e sua dura repressão alçou o feminino à cena pública.

Como descreve Neri (2005), o discurso científico da época, convidado a moldar os sujeitos em determinados papéis civilizatórios, recrudesceu uma mudança na visão sobre a mulher: Se antes era o "sexo diabólico", a bruxa que precisava ser queimada ao menor sinal de suposto pecado, agora passava à figura da "madona", o sexo da sensibilidade destinado à "verdadeira vocação feminina": a maternidade (Neri, 2005, p. 105). Criou-se, assim, o mito da essência feminina, pautado pela submissão e domínio privado.

Esse mito restringiu as possibilidades de reivindicação da mulher a seu espaço na esfera pública, impossibilitando-a muitas vezes de seguir outro destino que não fosse o de sua "vocação". Além disso, as exigências culturais que recaiam sobre a mulher se estendiam a restrições a sua sexualidade, tendo ela que renunciar a uma atividade sexual. Essa renúncia vai aparecer em Freud (2015) como um dos fatores etiológicos das neuroses, quando o corpo feminino irrompeu em crises histéricas no século XIX.

O conflito entre sexualidade e cultura, recalque e desejo, demarcam o campo de superposição entre social e individual, com o ambiente cultural fornecendo o conteúdo para a formação dos sintomas.

Quando os outros saberes se mostraram insuficientes, a psicanálise emergiu propondo explicar e tratar a histeria a partir da singularidade e da escuta. São as mulheres inicialmente internadas na Salpêtrière, onde Freud estudou, e, posteriormente, ocupando o divã de seu consultório, que vão delineando o tratamento, a talking cure, e desvelando o enigma da sexualidade.

É justamente o feminino, na figura da mulher histérica, que demonstra a insuficiência do discurso da racionalidade iluminista, dando voz, enfim, ao que a todo custo tentava-se calar pela via da exclusão. Assim como a psicanálise é criada no seio de uma crise histérica que clama por escuta, o próprio movimento feminista é uma expressão criativa da irrupção da histeria como mal do século.

É por desvelar o inconsciente, por atestar no corpo e na fala a sua presença, que a histérica se torna o sujeito privilegiado da psicanálise. Ao subverter a visão do corpo como um aparato meramente fisiológico, por meio dos sintomas sem uma causa orgânica observável, rompe com a dicotomia mente e corpo, apresentando o corpo pulsional: "o corpo erógeno da histeria aponta para uma economia subjetiva corpórea; há um corpo libidinal que revela um excesso pulsional que as palavras não podem dizer" (Neri, 2005, p. 96).

A histérica também desconstrói o sexo determinado pela anatomia com seu questionamento sobre ser homem ou mulher, ressaltando a máxima de Simone de Beauvoir (2009) - também estendida aqui aos homens: não se nasce mulher, torna-se. 
É interessante notar que a teatralização da histérica já aponta para uma dimensão que, atualmente, é bem reconhecida no campo dos estudos de gênero, o fato de o sexo e o gênero não serem biológicos ou naturais, mas construídos. A psicanálise, enfim, também é construída em um contexto de irrupção do feminino na cena histórica e social que questiona os saberes da época, entre eles, a medicina. Mas ela não somente se funda nesse contexto, como também é tributária dele, do cenário que alçou o feminino ao centro dos discursos.

Apesar de psicanálise e feminismo terem sido fundados nesse movimento de irrupção na cultura, eles não seguem a mesma concepção de sujeito ou de feminino. Em um olhar inicial, as teorias feministas e a psicanálise partem de diferentes planos de análise, pois não compartilham a mesma concepção epistemológica de sujeito: as primeiras são tributárias do sujeito da consciência, especialmente da noção de identidade, enquanto, na psicanálise, a centralidade recai sobre o sujeito do inconsciente.

A concepção de feminino também difere entre os dois campos. Termo polissêmico, na teoria psicanalítica, remete aos polos opostos de feminino e masculino presentes no psiquismo que, como define Freud (1905/1996a), relaciona-se, em última instância, à passividade/castração e atividade/fálico que demarcam a diferença sexual.

Nas produções feministas, contudo, o feminino é fruto de construções sociais que estabelecem estereótipos de gênero, como a figura da mulher frágil e submissa. Para essas, o feminino, portanto, não possui o sentido disruptivo que receberá no segundo ensino lacaniano, nem se confunde com a posição feminina, pelo contrário, está mais próximo da aquisição de um gênero social (Miguel, 2014).

Mesmo assim, ambas as teorias mantiveram um intenso debate ao longo das décadas. O período de pós-Revolução Francesa até o início do século XX ficou conhecido como a primeira onda do movimento feminista, denominado, posteriormente, de feminismos da igualdade, devido à centralidade da luta por direitos, especialmente no que tange ao voto, ao trabalho e à educação. O debate inicial com a psicanálise foi marcado pela crítica à importância da anatomia para a diferença sexual e, em especial, à concepção de feminilidade marcada pela inveja do pênis e pela maternidade.

A partir da segunda metade do século XX, surgiu a corrente que ficou conhecida como "feminismo francês", influenciada pelos feminismos da diferença, a qual constituiu novas relações com a psicanálise de orientação lacaniana, tendo como cerne do debate o estatuto do simbólico por meio da crítica ao lugar do falo na psicanálise (Brennan, 1997).

Como afirma Knudsen (2007), a história de interlocução entre feminismo e psicanálise é marcada por críticas e apropriações, especialmente no que tange à análise do feminino:

A história do encontro entre feminismo e psicanálise não é apenas uma história de colaboração, mas é também uma história de confronto, tendo como foco a sexualidade feminina, a explicação da aquisição de gênero e o papel da psicanálise na reprodução da hierarquia entre os gêneros, resultando na desvalorização do gênero feminino. (Knudsen, 2007, p. 48)

Ao promover um rompimento epistemológico, afastando-se do método cartesiano com o trabalho do inconsciente, a psicanálise propõe-se a atuar numa posição de êxtimo aos referenciais tão caros ao método científico, como a racionalidade, a objetividade e as teorias sociológicas, por se afastar da análise pautada em referenciais conscientes. Logo, a análise da constituição da subjetividade a partir da clínica permitiria à psicanálise tanto explicar a produção e reprodução da identidade de gênero no sujeito (Scott, 1995) quanto os processos de assujeitamento e resistência às normatizações de gênero. A análise psicanalítica do sujeito complementaria a análise social.

\section{Traduções, Interpretações e Anacronismos: A Crítica Feminista à Psicanálise Freudiana}

Desde o início do século XX, interlocuções entre psicanálise e teorias feministas vêm sendo tecidas, com o debate freudiano inicial marcado pelo duplo movimento de reconhecimento e crítica. Reconhecimento por propor o rompimento da sexualidade com a biologia, descolando a reprodução do prazer sexual e indicando a plasticidade da pulsão, ao invés da predeterminação do instinto; e crítica à importância atribuída à anatomia para a diferença sexual, em especial na concepção de feminilidade.

Em meados da década de 1920, com a publicação das polêmicas teses lançadas no artigo Algumas consequências psíquicas da diferença anatômica entre os sexos (Freud, 1923/2011a), surge o primeiro grande debate sobre a sexualidade feminina, tanto no interior quanto fora do movimento psicanalítico. No centro do debate, a tese acerca do complexo de castração feminino.

No momento histórico no qual as mulheres começaram a reivindicar posições semelhantes às dos homens, as concepções de Freud (1923/2011a), marcadas por uma clara distinção entre "homem" e "mulher" - sendo o primeiro dotado de um superego mais bem desenvolvido e uma tendência maior à moralidade e ao trabalho de civilização, enquanto nas mulheres poderíamos observar um superego frágil e uma tendência ao masoquismo, à passividade e à histeria -, foram alvo de intensas críticas.

Freud (1924/2011b, p. 211) volta suas pesquisas sobre a sexualidade feminina para o peculiar caminho edípico pelo qual a menina seguirá. Desse modo, descreve que a menina, ao deparar-se com um "camarada de brinquedos do sexo masculino", presume que teve, em algum momento, o mesmo órgão sexual, mas o perdeu, e ainda atribui à sua mãe e às outras mulheres 
o órgão genital completo. Demarca-se aí uma diferença fundamental entre os dois sexos: a percepção da diferença entre os órgãos sexuais masculino e feminino coloca a menina na situação de já ter perdido o pênis, portanto castrada, enquanto o menino, ainda portador do órgão, ao ver a diferença, teme que a mesma perda ocorra com ele. Logo, na menina, é o complexo de castração que introduzirá o Édipo, enquanto no menino o temor da castração produzirá sua dissolução.

Ao perceber-se castrada, a menina alimenta a fantasia de que o homem é aquele que pode lhe dar o que falta, promovendo um deslocamento da sua libido da mãe para o pai, já que aquela é tomada agora como rival. Destituída da sua ilusão de masculinidade - possuidora de um pênis - resta receber de volta, da figura paterna, uma compensação, o pênis na forma de um bebê.

O complexo de Édipo feminino segue marcado por três saídas possíveis frente ao imbróglio da castração: a primeira corresponderia à inibição neurótica, em que a percepção da diferença sexual produz um sentimento de inferioridade quanto a seu órgão, levando a menina a abandonar completamente qualquer atividade sexual; na segunda, mantém a crença de que irá, em algum momento, possuir um pênis, ficando atrelada, assim, a uma fantasia masculina; na última, identificada com o pai e tomando a mãe como objeto de amor, adquirirá características "masculinas".

Somente se seu desenvolvimento seguir o caminho "normal", o da identificação com a mãe, ela alcançará a feminilidade. É certo que as saídas apresentadas neste texto são descritas como ideais, pois nenhuma dessas "resoluções" é completa, visto que masculino e feminino não se apresentam como categorias binárias mutuamente excludentes, como afirma em texto anterior: "as reações dos indivíduos de ambos os sexos são mesclas de traços masculinos e femininos" (Freud, 1923/2011a), p. 294).

A feminilidade seria o caminho mais tortuoso e indireto, marcado por um trabalho a mais, no qual, ao final, a menina chegará à sexualidade feminina normal, caracterizada pelas duas trocas que ela precisa operar para tornar-se mulher: uma mudança de objeto da mãe para o pai e uma mudança de zona erógena, do clitóris para a vagina, o que implica passar da posição ativa para a passiva.

O desejo de um bebê como substituto do pênis constitui o cerne da sexualidade feminina adulta, marcada pela maternidade. O desejo de que um homem lhe dê um filho leva a menina a identificar-se com o aquilo que a mãe possui e a levou a conquistar o pai, sua feminilidade. A feminilidade, entretanto, não implica um abandono do desejo pela posse fálica, mas apenas seu adiamento, visto que se tornar feminina é um meio necessário para futuramente recobrar a posse do pênis na forma de um filho.

Logo, a maternidade é, concomitantemente, um anseio feminino e masculino da mulher freudiana, a qual parece nunca abandonar completamente seu anseio masculinofálico, sendo eternamente condenada a invejá-lo e a mascarar a inveja com os atributos sedutores da feminilidade para conseguir, enfim, a posse fálica na forma de um filho.

A concepção de uma sexualidade feminina originada de uma masculinidade delineia as teses freudianas, fazendo do tornar-se mulher um processo complicado e indireto, enquanto o tornar-se homem, a masculinidade como ponto de chegada, é tomado como fato dado, "quase uma evidência" (Arán, 2006, p. 51).

É por uma fase - e com ela a oposição subjacente - não superar ou apagar a outra que o feminino é constituído sobre o polo castrado e o masculino, sobre o fálico. Disso resulta que, por estar no polo castrado, faltam referenciais identificatórios para a menina, pois ela não pode se identificar com um atributo ausente. Diante disso, resta à menina identificar-se com a mãe em sua feminilidade, tecendo um certo referencial identificatório, e procurar o falo de outra maneira, pela via da maternidade.

Se é o representante falo, a sua presença ou ausência, que organizaria a sexualidade, ou seja, se a masculinidade é originária, então a feminilidade seria sempre uma construção secundária. Segundo Ribeiro, Lamarca, Fonseca, e Junqueira (2005), é justamente pela posição feminina não ter representação na infância, por ela não constituir representação inconsciente, que as mulheres precisam construir seu próprio referencial de feminilidade sem um suporte simbólico, recorrendo à sua própria experiência, usualmente com a mãe, e aos demarcadores fornecidos pela cultura.

Essas teses foram - e ainda são - fonte de polêmicas entre as feministas, que denunciam uma espécie de misoginia nas formulações freudianas. Sua construção teórica foi frequentemente vista como essencialista, por manter um único caminho "normal" de desenvolvimento, que seria o da maternidade, com a inveja do pênis como um dos principais pontos de crítica, por ser considerada uma leitura datada das mulheres vitorianas de Viena, que não poderia ser entendido como componente universal da sexualidade feminina (Friedman, 1971). Vítimas da inveja do pênis, o anseio feminino estaria marcado pela passividade e maternidade, sendo qualquer recusa a estas concepções tomadas como uma tentativa de tornar-se homem.

A primazia fálica, frequentemente relacionada ao pênis, também não tardou a causar polêmica, com as acusações sobre o falocentrismo freudiano. Rubin (1993) tece uma crítica à concepção do falo enquanto elemento estruturante do psiquismo, produtor de uma diferença entre meninos e meninas, em que estas últimas ocupariam um polo negativo, além de propor uma concepção de sexualidade normativa pautada pela heterossexualidade. Conforme descreve a autora:

Nesse sentido, o phallus [falo] é mais que um traço que distingue os sexos: ele é a personificação do status de macho, ao qual os homens ascendem e ao qual certos direitos são inerentes - entre eles, o direito a uma mulher. É uma expressão da transmissão da dominância masculina. Ela passa pelas mulheres, mas se assenta nos homens. Os rastros que deixa incluem a 
identidade de gênero, assim como a divisão dos sexos. Porém, ela deixa mais do que isto. Ela deixa a "inveja do pênis", que adquire uma rica significação da inquietação das mulheres numa cultura fálica. (Rubin, 1993, p. 17)

Rubin inicia esse debate-atualizando uma crítica já realizada no interior do próprio movimento psicanalítico, dirigida à ideia de que a sexualidade feminina é marcada pela inveja do pênis e pelo falicismo. A crítica centra-se especialmente no referencial fálico como organizador da subjetividade humana e as consequências deste referencial para uma teoria sobre a identidade de gênero na psicanálise: a dominância masculina marcada pelo registro do falo implicaria a manutenção de uma assimetria entre os sexos.

"A psicanálise é uma teoria feminista manquée" (Rubin, 1993, p. 14). A psicanálise seria uma teoria feminista incompleta, inacabada, porque, para a autora, todo o caminho da feminilidade/masculinidade, que poderia tecer uma teoria crítica sobre a aquisição do gênero, ao fornecer a descrição de como a bissexualidade constitutiva se transformaria em diferentes papéis de gênero, permaneceu apenas como potencial não explorado, tanto pela psicanálise quanto pelo movimento feminista.

No entanto a psicanálise também foi reconhecida por suas contribuições ao feminismo, especialmente no que tange ao rompimento da sexualidade com a biologia, descolando a reprodução do prazer sexual e indicando a plasticidade da pulsão ao invés da predeterminação do instinto.

A própria maternidade como a saída "normal" para mulher pode ser lida não como uma posição universal à qual as mulheres são destinadas, mas como a via possível ao tempo no qual Freud viveu. O que o discurso freudiano parece colocar em pauta não é um caminho universal ao qual uma disposição psíquica impele a mulher, mas, na verdade, parece traduzir a única identificação permitida à mulher de acordo com os ideais de seu gênero: a identificação com a posição de mãe.

Segundo Kehl (2008), esta seria a única possibilidade libidinal para a mulher na cultura ocidental dos últimos séculos, devido à interdição de outras possibilidades identificatórias:

O que está barrado para a mulher freudiana não é uma outra possibilidade de evolução nos destinos da libido a partir das dificuldades que ela tem de enfrentar o Édipo; o que a cultura ocidental dos séculos XVIII, XIX e começo do século XX interditou às mulheres foram outras possibilidades identificatórias, a única identificação permitida para a menina, de acordo com os ideais de seu gênero, e que lhe promete alguma perspectiva de gratificação libidinal, é a identificação à mãe, não enquanto mulher no sentido amplo (esta mulher ainda não existia), mas apenas na posição materna. (Kehl, 2008, 211)

É na maternidade, por conseguinte, que o peso desse discurso mostra toda a sua força. O ideal de mãe passou a ser incentivado como algo natural, o instinto materno, e não como uma construção ideológica. $\mathrm{O}$ tornar-se mãe, e não mulher, seria um ponto final em si, na moral vitoriana vigente, mas a mãe não é uma mulher, sofre o peso da deserotização, conforme descreve a autora, e talvez, justamente por isto, Freud não conseguiu avistar outras possibilidades possíveis, outros objetivos na vida da mulher.

Logo, a contribuição freudiana manteve-se nessa época imersa nesse paradoxo: ao mesmo tempo em que desnaturalizava a sexualidade humana, apontava, no que se refere especialmente à mulher, caminhos essencialistas e voltados para a esfera privada.

Por um lado, não podemos deixar de notar que as teses freudianas de uma assimetria entre homens e mulheres, pendendo negativamente contra as últimas, assim como a ideia da maternidade como um "destino", podem ter contribuído, de certa forma, para a manutenção da posição social da mulher, como a crítica feminista afirma. Por outro lado, é preciso apontar certo anacronismo nessa leitura freudiana que, por vezes, não reconheceu sua origem clínica, enquanto leitura de uma época, e o referencial pelo qual estava marcado. Somente no retorno à Freud, proposto por Lacan, que a discussão acerca do falocentrismo ganhou novos contornos, ao partir de sua leitura simbólica.

\section{A Querela do Falo: Sujeição e Resistência em Psicanálise}

A partir da década de 1960, as tensões entre psicanálise e feminismos ganham novos contornos. Ambos os movimentos passaram por um contexto de renovação: na psicanálise, houve o retorno a Freud, proposto por Lacan, a partir da crítica à centralidade das relações de objeto, alçando o simbólico o patamar de elemento central da análise (Lacan, 1995).

No texto O Simbólico, o imaginário e o real, Lacan (2005) introduz os três registros fundamentais na experiência humana. Comentando o trabalho analítico, define-os da seguinte maneira: o simbólico é a linguagem, o sistema de representações, os significantes dados pelo grande Outro que constituem o sujeito e que o habita. O inconsciente, portanto, é estruturado como linguagem, porque é por meio dela que pode se manifestar. O imaginário, inserido também na ordem da linguagem, diz respeito à relação com o pequeno outro, o semelhante e a constituição do corpo; enquanto o real é da ordem do impossível, do que resiste a toda simbolização.

Por sua vez, influenciado pelo Maio de 1968, o movimento feminista entra em sua segunda onda, conhecida como os feminismos das diferenças, que mantiveram a luta por igualdade a partir de uma perspectiva cultural e política, de afirmação 
das diferenças em termos de sexualidade, linguagem e mentalidade (Lacan, 2012). Tratou-se, portanto, de tornar as experiências privadas das mulheres a força motriz para o questionamento público.

Lutas específicas com acentuado caráter de contestação social começaram a se delinear, tais como: direito da mulher sobre seu próprio corpo, aborto, inserção no mercado de trabalho e equiparação salarial. Paulatinamente, a categoria mulher vai dividindo espaço, no interior do movimento feminista, com a categoria gênero, definida, em linhas gerais, como a organização social dos sexos, uma divisão pautada não mais na natureza, mas em uma construção social (Scott, 1995).

O debate entre psicanálise e feminismo não tardou a reverberar essa mudança, com a produção teórica marcada por duas linhas de pensamento: a primeira, anglo-americana, para a qual a psicanálise surge como uma via de explicação dos componentes inconscientes da feminilidade e o que neles torna a opressão da mulher tão arraigada e persistente na sociedade (Chodorow, 1990); a segunda, que recebeu a alcunha de feminismo francês, influenciada pelos feminismos da diferença, tinha como cerne do debate o estatuto do simbólico por meio da crítica ao lugar do falo na psicanálise (Brennan, 1997).

A escola anglo-americana de relações de objeto despontou nos estudos de gênero tecendo uma crítica à reprodução dos papéis de gênero e do lugar relegado à mulher, que impõe a maternidade como um instinto natural, enquanto seria, na verdade, um dos caminhos identificatórios. Privilegiando a importância do Eu relacional, ou seja, a constituição do Eu na relação mãebebê, Chodorow (1990) criticou a centralidade do complexo de castração e da diferença sexual na psicanálise e como este levaria a uma identificação ao gênero que seria resultado da internalização das relações sociais que organizam a função paterna.

Ao manter-se atrelada ao componente anatômico da diferença sexual e da concretude com que trata as relações parentais, a primeira corrente foi criticada tanto pelas feministas, por obliterar o papel dos sistemas sociais, econômicos e políticos e centrar-se exclusivamente na interação dos pais com a criança, como pelos analistas, por reduzir o estatuto do inconsciente à esfera do social, transformando a diferença sexual em resultado da organização social, e não como fundamento da ordem simbólica (Scott, 1995).

Apesar da crítica, essa corrente marcou fortemente a relação teórica entre psicanálise e feminismo no Brasil, por serem as primeiras traduções a aportarem no país. Ao longo da década de 1970 e 1980, época do início da organização do movimento feminista brasileiro e da incorporação desses estudos no ambiente acadêmico, foram - e ainda são - as autoras filiadas à tradição anglo-americana que mais se difundiram nas discussões brasileiras (Lago, 2010).

Já para o feminismo que incorpora a orientação lacaniana, a psicanálise desponta como uma terceira via de estudos, ao lado da historiografia das mulheres e das teorias que explicariam as causas para a subordinação feminina, ao permitir uma análise da subjetividade por meio da inserção na matriz simbólica.

Como dito anteriormente, para essa corrente, o simbólico possuiria uma natureza patriarcal e falogocêntrica devido à dominância masculina demarcada pelo registro do falo, o que implicaria na manutenção de uma assimetria entre os sexos. Para Brennan (1997, p.13), o falo, enquanto representante da diferença sexual, seria "a diferença crucial para que se possa falar e, portanto, pensar", sendo que "o reconhecimento visual da diferença sexual é um canal que liga a experiência heterogênea do corpo sensível, sensorial, a algo alheio a ele: a estrutura diferencial da linguagem". O falo, portanto, seria um significante "neutro" somente em sua vertente não visual, mas, ao ligar-se ao corpo, mais especificamente ao pênis, teria nesse representante visual a relação entre corpo e estrutura de linguagem, deixando de ser neutro para ser representado de modo masculino e unilateral. Confirmar-se-ia, assim, a natureza patriarcal e falogocêntrica do simbólico.

Em outras palavras, num plano não-visual, o falo não deveria ser senão um sinalizador neutro: um significante que nada represente, ou nada mais represente do que aquela falta que nos impele a falar, e, ao falar, nós nos diferenciamos. Entretanto, ao ligar o corpo a esse processo de reflexão, nós confiamos na representação visual da diferença sexual. Daí que o falo idealmente neutro é representado de um modo masculino unilateral. (Brennan, 1997, pp. 13-4)

O masculino dominaria pela presença, e a racionalidade seria estabelecida por meio da exclusão do feminino. Se a presença é um privilégio e um sexo é presente enquanto outro é ausente, apenas por um sexo ser mais visível que o outro já conferiria a este um privilégio. A resposta política possível para essa vertente seria, portanto, analisar as possibilidades de um simbólico não-patriarcal e o que ele acarretaria em termos de diferenciação.

Logo, enquanto a primeira vertente centra-se na concretude da família e da divisão dos papéis entre os pais para propor sua subversão com o intuito de criar igual acesso ao simbólico; a segunda expõe a relação entre pênis e falo para rejeitar um simbólico falogocêntrico, que marcaria a feminilidade como o lugar da diferença.

No que tange ao imbróglio entre falo e pênis, desde Freud (1923/2011c), a psicanálise já busca esclarecer a sexualidade feminina e masculina e a sua diferenciação, sendo o falo um organizador na passagem da bissexualidade constitutiva para um ser sexuado, que orienta a economia psíquica em ambos os sexos.

Apesar do termo pênis se fazer mais presente do que falo na obra freudiana, o autor reitera, em $A$ organização genital infantil (Freud, 1923/2011c, p. 171), a primazia do falo, contudo sem desconsiderar a relação entre ambos, afirmando que a 
principal característica da organização genital infantil “(...) consiste no fato de que, para ambos os sexos, apenas um genital, o masculino, entra em consideração. Não há, portanto, uma primazia genital, mas uma primazia do falo".

Segundo André (1998), essa virada em sua produção teórica indica que não se trata mais de afirmar a primazia de um pênis presente nos meninos, mas sim da demarcação da falta, a castração:

Não é mais a universalidade do pênis que ele encontra na atitude das crianças mas, de modo mais sutil, o primado do falo. Este termo introduz uma nuance: se o falo tem uma relação íntima com o órgão masculino, é na medida em que designa o pênis enquanto faltoso ou suscetível de vir a faltar. Retornando à observação do menininho que descobre a anatomia feminina, Freud explicita, então, que não é o pênis, enquanto tal, cuja existência é afirmada na menina, mas o pênis enquanto cortado. (André, 1998, p. 172)

Contudo, na teoria freudiana, se o falo introduz a dimensão da falta, ele ainda o faz inaugurando caminhos diferentes para meninos e meninas a partir da anatomia. A relação entre pênis e falo, como analisa Neri (2005), parece ainda determinar um sexo universal sobre o qual a sexualidade feminina seria deduzida, sofrendo, com isso, consequências psíquicas próprias, como a castração, a inveja do pênis e a maternidade como saída compensatória.

É dessa forma paradoxal que a teorização freudiana avança de acordo com as possibilidades de sua época. É somente com Lacan (1995) que o falo ganhará um novo estatuto, de significante, e sua dimensão de falta será retomada na discussão sobre os três registros da falta, quando analisa a passagem do falo de um objeto imaginário do desejo materno ao simbólico. É a partir da introdução do pai real na equação mãe-filho-falo que se instituirá um quarto elemento para operar a castração materna, barrando o desejo da mãe e introduzindo a falta simbólica do falo.

A incidência da função paterna, por meio da introjeção da lei do tabu do incesto, regulamenta as trocas humanas e oferece a estrutura simbólica à criança. O falo, que antes era um objeto imaginário na dialética da frustração, torna-se um objeto simbólico que falta para ambos os sexos.

A partir desse momento de virada, o objeto não é mais o objeto imaginário com o qual o sujeito pode tapear, mas o objeto sobre o qual um Outro é sempre capaz de mostrar que o sujeito não o tem, ou o tem de forma insuficiente. Se a castração exerce esse papel essencial para toda a continuação do desenvolvimento, é porque ela é necessária à assunção do falo materno como um objeto simbólico. Somente a partir do fato de que, na experiência edipiana essencial, ela está privada do objeto por aquele que o tem, que sabe que o tem, que o tem em todas as ocasiões, é que a criança pode conceber que este mesmo objeto simbólico lhe será dado um dia. (Lacan, 1995, p. 213)

A castração reordena as relações do sujeito com a falta e fornece um novo estatuto ao falo, como significante da falta, ordenando o desejo. Deixa, portanto, de ser um objeto imaginário e passa a ter a função significante que referencia todo o desejo do homem e da mulher. A castração, aponta Lacan (1999, p. 139), não incide sobre os órgãos sexuais, masculinos ou femininos:

Na verdade, essas discussões mostram bem que a coisa de que se trata não é nem isso nem daquilo. É algo que tem uma certa relação com os órgãos, mas uma certa relação cujo caráter significante, desde a origem, não deixa dúvidas. É o caráter significante que predomina.

Logo, diferentemente do que apontam uma miríade de discussões entre autores pósfreudianos, a castração não está ligada a um objeto da realidade, ao pênis ou ao clitóris, mas à produção do desejo, “(...) está ligada inclusive a evolução, ao progresso, à maturação do desejo no sujeito humano" (Lacan, 1999, p. 318). A castração seria uma renúncia de gozo, não do pênis ou de um órgão anatômico, aplicando-se a homens e mulheres.

Se, portanto, por um lado, o falo aponta para a falta em ambos os sexos, também marca diferentes posições para os sexos: enquanto o masculino, definido pelo significante fálico, ocupa a posição dialética do ter na escolha de objeto amoroso, possuindo no corpo o suporte imaginário, o feminino ocupa a posição do ser, faz semblante de ser o falo para o homem que a deseja, imaginariamente pelo menos.

Por mais paradoxal que possa parecer essa formulação, dizemos que é para ser o falo, isto é, o significante do desejo do Outro, que a mulher vai rejeitar uma parcela essencial da feminilidade, nomeadamente todos os seus atributos na mascarada. É pelo que ela não é que ela pretende ser desejada, ao mesmo tempo que amada. Mas ela encontra o significante de seu próprio desejo no corpo daquele a quem sua demanda de amor é endereçada. (Lacan, 1998b, p. 701)

Chegamos aqui em um ponto nodal da experiência psicanalítica, no qual convergem as críticas feministas: ao mesmo tempo em que postula uma falta que organiza a subjetividade humana, as consequências dessa falta não deixam de ser marcadas 
por um significante fálico. Contudo menos por um suporte na anatomia e mais pela falta de um significante específico que represente o sexo feminino - o que, posteriormente, foi traduzido no aforismo lacaniano A mulher não existe (Lacan, 1985).

Ao afirmar que o inconsciente não reconhece a diferença entre os sexos, apenas a primazia do falo, Freud (1924/2011b, p. 175) estabelece uma mudança na polaridade ativopassivo da organização genital infantil: “(...) há masculino, mas não feminino; a oposição é genital masculino ou castrado. Apenas ao se completar o desenvolvimento, na época da puberdade, a polaridade sexual coincide com masculino e feminino". Como consequência, a posição feminina não tem representação na infância, ela não constitui representação inconsciente, sendo necessário que as mulheres construam, uma a uma, seu próprio referencial de feminilidade sem um suporte simbólico, recorrendo à sua própria experiência, usualmente com a mãe, e aos demarcadores fornecidos pela cultura.

Nos primeiros escritos de Lacan (1998b) temos, no entanto, a função do falo enquanto significante da falta. Mais do que representar a diferença sexual, estabelecendo diferentes posições na dialética do ser e do ter para os sexos, se presta a representar a falta constituinte em ambos os sexos, ou seja, sua vertente estruturante. Por mais que essa função implique em consequências para a partilha dos sexos, ainda assim não se trata de consequências para as identificações ao gênero. O plano no qual a relação entre pênis e falo pode até ser mantida, e que suportaria as construções sociais constituintes do gênero, é outro que não o do sujeito do inconsciente, afinal, o sexual não se confunde com o sexuado.

Além de sustentar um determinismo anatômico, calcado numa equivalência imaginária que a psicanálise há muito procura romper, as teorizações que partem da crítica à noção de um simbólico falogocêntrico que precisa ser implodido parecem também partir da concepção de sujeito da consciência, com uma identidade que se constitui como base do Eu e toma o inconsciente como objeto para o Eu, sobre o qual se pode intervir ou rejeitar conscientemente. Perde-se, com isso, a radicalidade da psicanálise, cuja ênfase é na relação do sujeito com a sua modalidade de gozo, como cada sujeito responderá sintomaticamente frente ao que da sexualidade resiste a toda simbolização, em detrimento das distinções de gênero, sexo e orientação sexual.

Ademais, essa vertente do debate feminista com a psicanálise, marcadamente influenciada por uma crítica do falo e do registro simbólico na explicação da diferença sexual no plano consciente, avança claudicante nas formulações ulteriores de Lacan (2012). Nessas formulações, o complexo de Édipo passa a versar cada vez menos sobre as identidades sexuais, tornandose um modelo central de explicação da entrada no simbólico e de identificação na estrutura de linguagem (Ambra, 2014).

\section{Feminino, uma Frente ao Conservadorismo?}

Se nesse momento temos, ainda, a indecifrabilidade da relação pré-edipiana pelo registro fálico, em Análise terminável e interminável (Freud, 1937/1996b) teremos os esboços de um novo registro para além do fálico-edípico, o da feminilidade originária. Marcando a proximidade entre feminilidade e pulsional, Freud oferece uma nova definição sobre a primeira: se, nos textos anteriores, a feminilidade é um dos destinos possíveis ao final de Édipo, um ponto de chegada para a sexualidade feminina; aqui a feminilidade aparecerá no lado oposto do caminho, como ponto de saída do humano.

A inveja do pênis na mulher e a luta contra a passividade no homem erigem-se na análise como defesas frente à feminilidade. Segundo Arán (2006), a construção desse conceito advém da virada metapsicológica e da teorização acerca da pulsão de morte, que demonstrava os limites de um trabalho analítico calcado somente na associação livre frente ao problema da compulsão à repetição. O que a compulsão à repetição demonstraria é um limite para a interpretação, um limite que demarca o campo de representação da lógica fálica que não recobriria o excesso pulsional irrepresentável da pulsão de morte, presente na compulsão.

Ao colocar a inveja do pênis e o protesto masculino, assim como o repúdio à feminilidade, como limite à análise, em um campo limítrofe entre o psíquico e o biológico, cujas esferas a possibilidade de representação não recobre completamente, Freud aponta, ao mesmo tempo, "um limite da técnica psicanalítica como também das subjetividades ancoradas em uma lógica fálica" (Arán, 2006, p. 12). Existiria todo um campo, portanto, não recoberto pelo registro fálico; um campo de excesso pulsional que comporia o território da feminilidade.

Lacan (1985) retoma essa concepção freudiana sobre a feminilidade para desenvolver suas teses sobre a posição feminina e masculina, a partir das tábuas da sexuação, com o feminino aparecendo em oposição ao registro fálico, não excluída deste, mas não-todo gozando falicamente.

$\mathrm{O}$ feminino começa a aparecer em sua aproximação com o real por ser o que escapa à representação, ocultando e desvelando uma ausência e evitando, assim, qualquer forma de "confinamento categórico" (Dunker \& Barbero, 2010, p. 31). Entretanto é somente a partir do Seminário 20: Mais, ainda (Lacan, 1985), que essas formulações serão desdobradas, na teorização lacaniana, em outra maneira de ler a questão da diferença sexual.

Se, no primeiro ensino, Lacan recorre ao significante fálico para tratar de uma dificuldade que vem desde Freud: a de tentar esclarecer quais as diferenças entre as posições masculina e feminina; a partir de 1970, recorrerá à teorização sobre duas modalidades de gozo, ao invés da unicidade fálica presente no Édipo (Dunker \& Barbero, 2010). 
Retomando a concepção freudiana da bissexualidade constitutiva, Lacan (1985) propõe a partilha dos sexos a partir da existência de um bigozo: Um gozo relativo à função fálica, ligado ao masculino, o Gozo Fálico, e um outro tipo de gozo: um gozo suplementar, o gozo do Outro, gozo feminino, para além do falo. O gozo fálico situa-se em constante relação com o significante, vinculado ao simbólico, que contorna um corpo pelo processo de nomeação e significação de suas partes. O Outro gozo é um gozo do corpo, que, diferentemente do fálico, não é do que se diz sobre o corpo, por estar fora da linguagem, sem o recobrimento desta. A mulher, embora alienada ao significante, não é totalmente determinada pela função fálica, podendo experimentar, em potencial, tanto o gozo fálico, inscrito no registro simbólico, quanto esse outro tipo de gozo, um "gozo suplementar" (p. 99), para além do falo, uma vez que não toda mulher tem relação com o gozo fálico.

Não se trata mais de pensar a diferença sexual a partir de dois sexos anatômicos, mas a partir dos modos de gozo de cada sujeito. A posição masculina segue marcada pela estrutura do desejo, significada falicamente e submetida ao simbólico, enquanto a feminina responde ao excesso não recoberto completamente pela linguagem, Outro lugar. Pela impossibilidade de ser completamente simbolizado, aproxima-se do Real.

A relação com o significante fálico seria insuficiente para explicar as mulheres, logo, por uma exigência lógica, pelas mulheres não formarem conjunto devido à inexistência de uma exceção que faça a regra - todas as mulheres são castradas -, não há universalidade da posição feminina: as mulheres precisam constituir-se uma a uma. Estão, dessa forma, submetidas e não submetidas à lógica fálica, experimentam um gozo diferente do gozo sexual fálico, um gozo suplementar que é radicalmente Outro e não pode ser tornado todo significante.

Como afirma Soler (2005), a ordem instaurada pelos discursos não é capaz de recobrir completamente os corpos. Diante destes, apenas é possível oferecer um semblante fálico. Portanto, o que entendemos por sexo e gênero são posições simbólicas, pois o real do sexo indica não a anatomia na qual se pode descobrir uma verdade sobre o sujeito, mas justamente a impossibilidade de se dizer tudo sobre ele.

É a aproximação do feminino do registro do real que será introduzida por Lacan (1985) como um furo nos semblantes fálicos bem estabelecidos. Segundo Demes, Chatelard, e Celes (2011, p. 660):

A especificidade do feminino, anunciada por Freud como obscura e enigmática, de alguma maneira, é retomada por Lacan. Só que, em vez de signo da falta, ela passa a signo de uma falha, um furo, uma perda (Prates, 2001, p. 100). No semblante de algo da ordem do impossível, inominável, para sempre perdido, diz-se compreender o feminino. Algo da ordem do Real, sem lei, que não cessa de não se inscrever. A mulher como ser complementar, emblema da mãe primordial, não existe mais (a não ser fantasticamente). Ela se torna o significante da diferença, da alteridade; e a feminilidade, seu conceito.

O feminino aponta para uma outro lógica, para além do fálico, “(...) uma experiência de perda dos emblemas fálicos e de falência narcísica" (Demes, Chatelard, \& Celes, 2011, p. 655). No tornar-se sujeito algo cambia, falha, e o feminino desponta como essa figura da alteridade, que não pode ser confinado a uma identidade, representando, assim, a própria singularidade.

O feminino, portanto, surge como o elemento que, ao longo dos séculos, foi ocupa um lugar de resto na cultura ocidental e que se coloca, atualmente, rompendo os limites da identidade e da centralidade para impor uma leitura da singularidade (Arán, 2009). Logo, propor o feminino como campo de aproximação do debate entre psicanálise e feminismo é tanto questionar a psicanálise em sua leitura da alteridade, com uma nova perspectiva para pensar a diferença, quanto pensar um sujeito para o feminismo mais livre de confinamentos categóricos ou identitários, como a categoria sociológica mulher pode frequentemente recair. Para além de ser um elemento que permeia o surgimento e a consolidação da psicanálise como prática clínica e construção teórica, o feminino se apresenta como um campo de diálogo com outros saberes que pode promover furos e rupturas em uma política calcada na identidade.

\section{Referências}

Arán, M. (2006). O avesso do avesso: Feminilidade e novas formas de subjetivação. Rio de Janeiro: Garamond.

Arán, M. (2009). A psicanálise e o dispositivo da diferença sexual. Revista de Estudos Feministas, 17(3), 653-673.

Ambra, P. E. S. (2014). A noção de homem em Lacan: Entre discurso e lógica. In P. E. S. Ambra \& N. Silva Jr (Orgs.), Histeria e gênero (pp. 169-198). São Paulo: nVersos.

André, S. (1998). O que quer uma mulher? Rio de Janeiro: Jorge Zahar.

Beauvoir, S. (2009). O segundo sexo. Rio de Janeiro: Editora Nova Fronteira. 
Bento, B. (2006). A reinvenção do corpo: A sexualidade e gênero na experiência transexual. Rio de Janeiro: Garamond.

Brennan, T. (1997). Para além do falo - Uma crítica a Lacan do ponto de vista da mulher. Rio de Janeiro: Editora Rosa dos Tempos.

Butler, J. (2013). Problemas de gênero: Feminismo e subversão da identidade. Rio de Janeiro: Civilização Brasileira.

Chodorow, N. (1990). Psicanálise da maternidade - Uma crítica a Freud a partir da mulher. Rio de Janeiro: Editora Rosa dos Tempos.

Cossi, R. K. (2016). A diferença dos sexos: Lacan e o feminismo. Tese de Doutorado, Programa de Pós-Graduação em Psicologia, Universidade de São Paulo, São Paulo.

Demes, J. R., Chatelard, D. S., \& Celes, L. A. M. (2011). O feminino como metáfora do sujeito na psicanálise. Revista MalEstar e Subjetividade, 11(2), 645-667.

Dunker, C. I. L., \& Barbero, G. H. (2010). Lesbianismo e visibilidade. A peste, 2(1), 21-43.

Freud, S. (1996a). Três ensaios sobre a teoria da sexualidade (1905). In J. Strachey (Ed.), Edição Standard Brasileira das Obras Psicológicas Completas de Sigmund Freud (Vol. 7, pp. 3-66). Rio de Janeiro: Imago.

Freud, S. (1996b). Análise terminável e interminável (1937). In J. Strachey (Ed.), Edição Standard Brasileira das Obras Psicológicas Completas de Sigmund Freud (Vol. 23, pp. 225-270). Rio de Janeiro: Imago.

Freud, S. (2011a). Algumas consequências psíquicas da diferença anatômica entre os sexos (1923). In P. C. Souza (Ed.), Obras completas: O eu e o id, "autobiografia" e outros textos (1923-1925) (Vol. 16, pp. 183-299). São Paulo: Companhia das Letras.

Freud, S. (2011b). A dissolução do complexo de Édipo (1924). In P. C. Souza (Ed.), Obras completas: O eu e o id, "autobiografia" e outros textos (1923-1925) (Vol. 16, pp. 203-213). São Paulo: Companhia das Letras.

Freud, S. (2011c). A organização genital infantil (1923). In P. C. Souza (Ed.), Obras completas: O eu e o id, "autobiografia" e outros textos (1923-1925) (Vol. 16, pp. 168-175). São Paulo: Companhia das Letras.

Freud, S. (2015). A moral sexual "cultural" e o nervosismo moderno. In P. C. Souza (Ed.), Obras completas: O delírio e os sonhos na Gradiva, análise da fobia de um garoto de cinco anos e outros textos (1906-1909) (Vol. 8, pp. 359-388). São Paulo: Companhia das Letras.

Friedman, B. (1971). Mística feminina. Rio de Janeiro: Editora Vozes.

Kehl, M. R. (2008). Deslocamentos do feminino. Rio de Janeiro: Imago Ed.

Knudsen, P. P. P. S. (2007). Gênero, psicanálise e Juditth Butler - Do transexualismo à politica. Tese de Doutorado, Programa de Pós-Graduação em Psicologia Clínica, Universidade de São Paulo, São Paulo.

Lacan, J. (1985). O seminário, livro 20: Mais, ainda (1972-1973). Rio de Janeiro: Jorge Zahar.

Lacan, J. (1995). O seminário, livro 4: A relação de objeto (1956-1957). Rio de Janeiro: Jorge Zahar.

Lacan, J. (1998a). Função e campo da fala e da linguagem em psicanálise. In J. Lacan, Escritos (pp. 238-324). Rio de Janeiro: Jorge Zahar.

Lacan, J. (1998b). A significação do falo. In J. Lacan, Escritos (pp. 692-703). Rio de Janeiro: Jorge Zahar. 
Lacan, J. (1999). O seminário, livro 5: As formações do inconsciente (1957-1958). Rio de Janeiro: Jorge Zahar.

Lacan, J. (2005). O Simbólico, o imaginário e o real. In J. Lacan, Nomes-do-Pai (pp. 9-53). Rio de Janeiro: Jorge Zahar.

Lacan, J. (2012). O seminário, livro 19: ... Ou pior (1971-1972). Rio de Janeiro: Jorge Zahar.

Lago, M. C. S. (2010). Feminismo, psicanálise, gênero: Viagens e traduções. Revista Estudos Feministas, 18(1), 189-204.

Miguel, L. F. (2014). Identidade e diferença. In L. F. Miguel \& F. Biroli (Orgs.), Feminismo e política (pp. 79-92). São Paulo: Editora Boitempo.

Neri, R. (2005). A psicanálise e o feminino: Um horizonte da modernidade. Rio de Janeiro: Civilização Brasileira.

Perelson, S. (2006). A parentalidade homossexual: Uma exposição do debate psicanalítico no cenário francês atual. Revista Estudos Feministas, 14(3), 709-730.

Ribeiro, M. A. C., Lamarca, D. B., Fonseca, M. R. \& Junqueira, L. M. (2005). Mulher: Um sintoma para o homem? Revista Latinoamerican de Psicopatologia Fundamental, 18(1), 74-87.

Roudinesco, E. (1997). Théroigne de Méricout - Uma mulher melancólica durante a Revolução. Rio de Janeiro: Rocco.

Roudinesco, E. (2003). A família em desordem. Rio de Janeiro: Jorge Zahar.

Rubin, G. (1993). O tráfico de mulheres: Notas sobre a “economia politica do sexo”. Pernambuco: SOS Corpo.

Saffioti, H. I. B. (2004). Gênero, patriarcado, violência. São Paulo: Editora Fundação Perseu Abramo.

Scott, J. (1995). Gênero: Uma categoria útil para análise histórica. Educação \& Realidade, 20(2), 71-99.

Soler, C. (2005). O que Lacan dizia das mulheres. Rio de Janeiro: Jorge Zahar.

\section{Como citar:}

Oliveira, P. A., \& Nicolau, R. F. (2020). Feminino em Questão: Diálogos Contemporâneos entre Psicanálise e Feminismo. Revista Subjetividades, 20(Esp 2. O Contemporâneo à Luz da Psicanálise), e8974. http://doi.org/10.5020/23590777. rs.v20iEsp2.e8974

\section{Endereço para correspondência}

Paula Affonso de Oliveira

E-mail: pablohuascar@gmail.com

Roseane Freitas Nicolau

E-mail: rbelo@ufpi.edu.br

Recebido em: 03/02/2019

Revisado em: 19/11/2019

Aceito em: 26/04/2020

Publicado online: $28 / 11 / 2020$ 